\title{
DETERMINANTS AND COMPARISON OF JCR, SJR, AND SNIP RATINGS OF FINANCE JOURNALS
}

\author{
Thomas M. Krueger
}

Thomas M. Krueger, D.B.A., Professor of Finance, Accounting and Finance Department, College of Business Administration, Texas A\&M University, Kingsville, Thomas.krueger@tamuk.edu

\begin{abstract}
Concern regarding the authenticity of acceptance rates published by academic journals has resulted in renewed interest in alternative measures of journal and article quality. In fact, a field of research is developing regarding journal quality metrics, known as bibliometric research. Leading bibliometric metrics are the Journal Citation Reports (JCR) measure, SCImago Journal Rank (SJR) indicator, and Source Normalized Impact per Paper (SNIP). This study compares these metrics in an effort to determine whether a single measure is sufficient or a hybrid approach considering all three measures is required to accurately measure journal quality. Metrics are examined for the top finance journals, as chosen by the Chartered Association of Business Schools (CABS), an association of the 120 leading business schools in the United Kingdom. Bibliometric measures are found to be correlated with journal acceptance rate, launch date, and CABS' ranking of journals.
\end{abstract}


Keywords: JCR, SRJ, SNIP, acceptance rates, journal quality, journal ranking

DOI: http://dx.doi.org/10.15239/j.brcacadje.2018.07.01.ja01

\section{INTRODUCTION}

Across time, a variety of measures have been used to assess journal quality. Initially, it was necessary for journals to be refereed and more desirably blind refereed (see for instance, Crane (1967) Blank (1991)). This expectation gave way to the utilization of acceptance rates, which in turn has given way to impact factors. Journal impact factors are used by editors to court authors and readership. Probably more importantly to those reading this report, impact factors are used to evaluate individual scholars, departments, colleges, and universities on the basis of the journals selected for research publication. Because it is typically too early to gauge the value of a given article based on its citation by subsequent authors, evaluations regarding retention, tenure, promotion, and salaries are frequently based upon perceived journal quality. Harzing (2016) demonstrates the importance of recognizing the difference between impact factors by documenting how author reputation varies with the impact factor employed.

The impact factor most widely used in the scientific community is the Journal Citation Report (JCR) factor created by Thomson-Reuters (Moed, 2011). Like all impact factors, it is reportedly an authoritative measure of a journal's prestige and quality. Most experts agree that journal quality cannot be measured with a single number, but is instead a multi-dimensional concept. In order to properly understand the value of research, one has to have an understanding of these various metrics. The goal of this research is to help the reader improve their understanding of three popular metrics and how these metrics vary across commonly reported journal characteristics. As a vehicle to make such an analysis, this research uses the listing of top-quality finance journals presented 
by the Chartered Association of Business Schools (CABS). The main advantage and disadvantage of the various impact factors, as reported by CABS' Academic Journal Guide (2015, p. 10), are shown in figure 1:

Figure 1. Advantages and Disadvantages of Impact Factors.

The initial research hypothesis is that JCR, SJR, and SNIP provide similar rankings of journal quality, allowing administrators to base decisions on one measure. The first alternative hypothesis is that the journal quality appraisal varies across metrics and that multiple quality indexes should be used to assess performance. A second research hypothesis is that journal quality is not a function of a variety of journal characteristics. The second alternative hypothesis is that JCR, SJR, and SNIP tend to be biased towards journals with specified characteristics. Finally, the third research hypothesis, and one related to the second, is that various measures of journal quality have a similar sensitivity to specified journal characteristics. The third alternative hypothesis is that the identified characteristics have a diverse impact on the reported level of journal quality across JCR, SJR, and SNIP metrics. Among the characteristics studied in this report are acceptance rates, frequency of issue, launch dates, number of reviewers, nation of publication, and review style (i.e., blind, double blind, editorial). Since all measures are based on citations, it does not address the correlation between perception-based journal rankings and citation-based journal rankings, which has become a popular topic (see, for instance Bontis and Serenko (2009), Serenko and Dohan (2011), and Mahmood (2017)). However, it should be noted that the Chartered Association of Business Schools' (CABS') Academic Journal Guide is a subset of finance journals chosen on the basis of the perception of journal impact by leading experts in the finance field. According to the CABS' the primary motivation for the Academic Journal Guide is to provide clarity as to which journals to aim for, and where the best work in a given field tends to be found. 


\section{LITERATURE REVIEW}

\section{Bibliometric Research Development over the Years}

Living in their academic silos, professors often miss the exciting and undoubtedly stressful changes occurring in academia. One of these controversies is the issue of accurately assessing journal quality and thereby predicting article value. However, a short review of the recent literature shows that comparison of JCR, SJR, and SNIP is a popular topic in hard sciences (see, for instance, Ion et. al. (2017) for a discussion of journal metrics in medicine and Ghimire (2017) for a discussion of journal metrics in the medical sub-branch of anesthesiology) and social sciences (see, for instance, Bowrey (2016) for a discussion of these journals in law and Mingers and Yang (2015) for a discussion of these journal metrics in management journals). It has also become an international concern, with researchers in Europe (i.e., Gu and Blackmore (2017), Mexico (e.g., Arencibia-Jorge et.al. (2016), and Russia (e.g., Zibareva and Soloshenko (2016) providing a comparison of these journal metrics for journals published in their locale. The discussion of what counts as quality research is taking place in the foreground of the 2017 AACSBInternational's standards updates (AACSB, 2017) and letters from Texas A\&M University-Kingsville's Peer Review Team's consultants of past AACSB Presidents (Trapnall and Boxx, 2017) that approximately fifty percent of intellectual contributions should be in the form of peer reviewed journal articles.

In retrospect, the measurement of journal impact has been a popular and controversial issue for at least the past ninety years, ever since Gross and Gross' (1927) study of references to articles published in the fournal of the American Chemical Society. Within a few years of their article's publication, bibliometric analyses were made of journals in mathematics (Allen, 1929), geology (Gross and Woodford, 1931), and biochemistry (Henkle, 1935) disciplines. In 1972, Eugene Garfield (1972) proposed an impact factor based on the average number of citations in articles published during the two preceding years, which was the foundation of 
the JCR measure. This fairly simple, yet informative measure has proven useful to the point of guiding library purchase decisions according to Cameron (2005) and Althouse et al. (2009) well into this century. A historical perspective on impact factors is provided by Garfield (2012), while a very comprehensive compendium of key impact factor research is provided by Vanclay (2012). Although Vanclay argues that the Thompson Reuter impact factor, referred to as JCR in this study, has so many weaknesses that it requires a major overhaul, in the same edition Moed et al. (2012) argue that impact factors are very useful means by which to assess journals and articles.

This study adds a finance dimension to the quickly developing array of articles regarding bibliometric measures. For instance, Brown's (2011) occupational therapy study contrasts the impact factor across academic and practitioner journals. Hall (2011) demonstrates that bibliometric research is important in the tourism research industry and used by government officials and private parties. Instead of comparing journals, Ramos-Rodriquez and Ruiz-Navarro (2004) study the citation occurrence of Strategic Management fournal articles over twenty years.

\section{Limited Preview}

This completes the limited preview of this paper. Please visit the link below to purchase.

\section{Citation Information}

Krueger, Thomas M. "Determinants and Comparison of JCR, SJR, and SNIP Ratings of Finance Journals." The BRC Academy fournal of Education 7, no. 1 (2018): 1-35.. http://dx.doi.org/10.15239/j.brcacadje.2018.07.01.ja01 